\title{
Cerebral Dural Arteriovenous Fistula
}

\author{
P. TABRIZI, R.F. SPETZLER, C. MCDOUGALL, F.C. ALBUQUERQUE
}

Division of Neurological Surgery; Barrow Neurological Institute, St. Joseph's Hospital and Medical Center; Phoenix; Arizona

Management of cerebral dural arteriovenous fistulae (DAVFs) has long been a subject of debate. With the advent of liquid adhesive embolics and coils, endovascular treatment has been the procedure of choice for most DAVFs. Nonetheless, this modality alone may not completely cure some fistulae. Surgical intervention is warranted in such cases. Therefore, a multidisciplinary approach to cerebral DAVFs that involves combined endovascular and neurosurgical treatment will improve the efficacy of treatment ${ }^{4}$.

\section{Classification of Cerebral DAVFs}

Understanding the different types of cerebral DAVFs is crucial for determining the most suitable treatment modality. Cerebral DAVFs are classified into five types ${ }^{3,6}$. Types IV and V are reclassifications of type III.

Type I lesions are characterized by a normal direction of blood flow with one or more fistulae located between a meningeal artery and a dural venous sinus or dural meningeal vein. These lesions usually manifest with pulsatile tinnitus, bruit, or a cranial nerve deficit depending on their location ${ }^{4}$. Their overall clinical course is usually benign.

In contrast, Type II lesions are characterized by reversed blood flow caused by one or more fistulae draining into a dural sinus and pial sub- arachnoid vein. Symptoms related to venous hypertension or haemorrhage are common denominators. Type III lesions consist of direct drainage into subarachnoid veins located at or in the wall of dural sinuses. They drain retrogradely into a vein before draining into the sinus, which may or may not be patent. A patent sinus is seldom in direct communication with the fistula and is isolated from the remaining dural venous structures.

Type III lesions behave more aggressively than types I and II and usually manifest with haemorrhage or other manifestations of venous hypertension. Type IV lesions include type III lesions with venous ectasia. Finally, Type V lesions are type III lesions associated with drainage into spinal veins.

\section{Aggressivity of Cerebral DAVFs}

Along with the classification, the aggressivity of cerebral DAVFs has been studied in detail ${ }^{1}$. Features found to be conducive to aggressive behavior involve leptomeningeal venous drainage, variceal, or aneurysmal venous dilatation, and Galenic drainage. The site of the lesion does not contribute to this behavior. Typically, however, lesions near the dural incisura and in the floor of anterior cranial fossa present more aggressively than those located elsewhere ${ }^{1,6}$. 


\section{Treatment Modalities}

Therapeutic management of cerebral DAVFs is challenging. Information obtained from angiographic studies of cerebral DAVFs, including their pattern of venous drainage, the occurrence of major sinus thrombosis, the presence of leptomeningeal drainage, and the presence of dysplastic venous aneurysms, should be used to determine the best treatment modality.

A number of treatment modalities have been postulated: transarterial or transvenous embolisation, retrograde transvenous embolisation, ligature of the feeding arteries, or a combination ${ }^{2}$. The goal of treatment should include total obliteration of the lesion because recruitment of collateral blood flow and recanalization of the fistula are highly likely and increase the risk of haemorrhage. Before surgical resection, the treatment philosophy for an endovascular approach should involve elimination of the arterial input and pial venous outflow. Endovascular therapy, however, carries definite risks, primarily those of haemorrhage, stroke, and cranial nerve deficits.

These risks increase as access to the DAVF becomes more difficult. When the risks of endovascular therapy outweigh the benefit, it is advantageous to consider a surgical alternative. For giant or complex cerebral DAVFs such as ones involving the transverse or sigmoid sinus where extensive blood loss would be expected, surgical intervention supplemented with a cardiopulmonary bypass with deep hypothermic protection is effective in preventing massive exsanguination ${ }^{3,5}$.

Treatment of type I cerebral DAVFs is usually elective and directed toward the intractable bruit or cranial nerve deficit. The treatment is directed toward the arterial input, with embolisation of arterial feeders ${ }^{6}$. If the malformation drains into a sinus that can be sacrificed, transvenous embolisation with thrombogenic coils and liquid adhesive glues in conjunction with surgical ligature can increase the symptomatic cure rate. If, however, the sinus must be preserved, a complete cure may be difficult to achieve. Treatment of type II and higher lesions may be problematic because of the complexity of the arterial supply and the variable accessibility of the venous drainage by endovascular means.

Radiation therapy has been advocated for small lesions less than $25 \mathrm{~mm}$ in total diameter.
This modality has been less successful with larger lesions ${ }^{7}$.

Certain DAVFs are clearly treated best with surgery. These include frontal lesions fed from the ophthalmic artery through the ethmoidal branches and petrosal lesions that drain into superior petrosal vein. Both lesions are easily clipped at the venous side of the fistula.

\section{Conclusions}

An effective means of treating cerebral DAVF usually involves a multidisciplinary approach. Endovascular treatment alone can provide adequate treatment for most lesions. For lesions at specific locations and complex or giant lesions with inaccessible arteriovenous fistulae, preoperative embolisation may not achieve sufficient occlusion of the arterial feeders. In such cases, surgical intervention can be used as an adjunctive definitive treatment modality.

\section{References}

1 Awad IA, Little JR et Al: Intracranial dural arteriovenous malformations: factors predisposing to an aggressive neurological course. J Neurosurg 72: 839-850, 1990.

2 Barnwell SL, Halbach VV et Al: Complex dural arteriovenous fistulas. Results of combined endovascular and neurosurgical treatment in 16 patients. J Neurosurg 71: 352-358, 1989.

3 Dufour $\mathrm{H}$, Levrier $\mathrm{O}$ et $\mathrm{Al}$ : Resection of a giant intracranial dural arteriovenous fistula with the use of low-flow deep hypothermic cardiopulmonary bypass after partial embolisation: technical case report. Neurosurgery 48: 1381-1385, 2001.

4 Lucas CP, Zabramski JM et Al: Treatment for intracranial dural arteriovenous malformations: a meta-analysis from the English language literature. Neurosurgery 40: 1119-1130, 1997.

5 Meyer FB, Grady RE et Al: Resection of a large temporooccipital parenchymal arteriovenous fistula by using deep hypothermic circulatory bypass. Case report. J Neurosurg 87: 934-939, 1997.

6 Pelz DM, Lownie SP et Al: Intracranial dural arteriovenous fistulae with pial venous drainage: combined endovascular-neurosurgical therapy. Can J Neurol Sci 24: 210-218, 1997

7 Thompson BG, Doppman JL, Oldfield EH: Treatment of cranial dural arteriovenous fistulae by interruption of leptomeningeal venous drainage. J Neurosurg 80: 617623, 1994

Robert F. Spetzler, M.D. Neuroscience Publications Barrow Neurological Institute 350 W. Thomas Road Phoenix, AZ 85013

E-mail: neuropub@chw.edu 